\title{
A Comparative Evaluation between Fixation Techniques Using Lag Screws and Mini Plates in the Treatment of Parasymphysis Fracture.
}

\author{
Harsh Kumar', Manoj Kumar Thakur ${ }^{1}$ \\ ${ }^{1}$ Senior Resident, Department of Dentistry, Nalanda Medical College \& Hospital, Patna, Bihar, India.
}

\section{Abstract}

Background: Aim: The objective of this study was to compare the results of lag screws and mini plates in treatment of parasymphysis fracture. Subjects and Methods: Forty patients of age group 20-45 yr old with clinical and radiological evidence of the traumatic injury to the parasymphysis were included in this study and were randomly divided in two groups. In group A-two $2.5 \mathrm{~mm}$ lag screws were placed in 20 patients and in group B-two $2.5 \mathrm{~mm}$ mini plates were placed in 20 patients. The statistical analysis was done by using SPSS 15 . Results: The majority of patients in Group A, the time needed to complete the procedure ranges from 60 to $90 \mathrm{~min}(65 \%)$, while for the time range from 60 to 90 (55\%) and 90 to $120 \mathrm{~min}(35 \%)$ in Group B. The difference in time required for completion of the procedures between the two groups was found to be statistically significant. In Group A, the duration of post-operative swelling varies as it is minimum for 5 days in 13 patients (65\%) and maximum 15 days in 3 patients (15\%). In Group B, swelling was present for minimum 5 days in 14 patients (70\%) and maximum 15 days in 2 patients (10\%) Conclusion: Although the sample size is less to reach to any conclusion, the results of our study suggest that the use of lag screws in the fixation of mandibular fractures can be a very demanding procedures as lag screw technique for Parasymphysis fracture provide several advantages over Mini plates.

Keywords: Parasymphysis fracture, Lag screw, Miniplates.

Corresponding Author: Dr. Harsh Kumar, Senior Resident, Department of Dentistry, Nalanda Medical College and Hospital, Patna, Bihar, India.

Received: January 2019

Accepted: January 2019

\section{Introduction}

Mandibular fracture occurs more frequently than any other fracture of facial skeleton. The mandibular fractures mainly occur due to assaults, road traffic accidents (RTA), falls and sports injuries. ${ }^{[1]}$ Although there is a wide variance in the reported percentage of fractures of the anterior mandible, aggregate analysis places this at approximately $17 \%$ of all mandibular fractures. ${ }^{[2]}$ The goal of treatment of mandible fractures should be to return the patient to a preinjury state of function and aesthetics, restore proper function by ensuring union of the fractured segments and re-establishing preinjury strength; to restore any contour defect that might arise as a result of the injury; and to prevent infection at the fracture site. ${ }^{[3]}$

A variety of different treatment modalities have been described for surgical reduction and fixation of a mandibular fracture. Among them are closed or open reduction, extra oral open reduction and internal fixation with a reconstruction plate, intraoral open reduction and internal fixation using different mini-dynamic compression or noncompression plates and an intraoral approach with lag-screw fixation. ${ }^{[4]}$ Miniplate osteosynthesis was introduced to maxillofacial surgery by Michelet et al. in 1973. ${ }^{[5]}$ The lag screw technique in maxillofacial surgery was first advocated by Brons and Boering in 1970 and was later reintroduced by Niederdellmann et al. ${ }^{[6]}$

The aim of the present study was to compare the results of lag screws and mini plates in treatment of parasymphysis fracture.

\section{Subjects and Methods}

Forty patients of age group 20-45 yr old with clinical and radiological evidence of the traumatic injury to the parasymphysis reporting to the OPD of Department of Oral and Maxillofacial Surgery were included in this study and were randomly divided in two groups. The study was approved by Ethical Committee. In group A-two $2.5 \mathrm{~mm}$ lag screws were placed in 20 patients and in group B-two $2.5 \mathrm{~mm}$ mini plates were placed in 20 patients. The patients with fracture of parasymphysis region of mandible with no evidence of pus discharge, patients who were medically fit for surgery under general anesthesia or local anesthesia and who were willing for surgery, patients within the age group of 20-45 years were included in the study. Patient with Comminuted mandibular fractures, pathologic fractures, hematological disorders and any other associated midface fracture were excluded from this study. The statistical analysis was done by using SPSS 15.

\section{Results}


40 patient with traumatic injury to the parasymphysis requiring open reduction and internal fixation were included in this study. In group A-two $2.5 \mathrm{~mm}$ lag screws were placed in 20 patients and in group B-two $2.5 \mathrm{~mm}$ mini plates were placed in 20 patients. In our study, male patient was predominant. Out of 40 patients $70 \%$ were male and $30 \%$ female.

The majority of patients in Group A, the time needed to complete the procedure ranges from 60 to $90 \mathrm{~min}(65 \%)$, while for the time range from 60 to $90(55 \%)$ and 90 to 120 $\min (35 \%)$ in Group B. The difference in time required for completion of the procedures between the two groups was found to be statistically significant [Table 1].

In Group A, the duration of post-operative swelling varies as it is minimum for 5 days in 13 patients $(65 \%)$ and maximum 15 days in 3 patients (15\%). In Group B, swelling was present for minimum 5 days in 14 patients (70\%) and maximum 15 days in 2 patients (10\%) [Table 2].

\begin{tabular}{|l|l|l|l|}
\hline Table 1: Comparison of time required for procedures. \\
\hline $\begin{array}{l}\text { Time required } \\
\text { for completion } \\
\text { of procedure } \\
\text { (min) }\end{array}$ & $\begin{array}{l}\text { Group } \\
\mathbf{n = 2 0}(\%)\end{array}$ & $\begin{array}{l}\text { Group } \\
\mathbf{n = 2 0}(\%)\end{array}$ & P value \\
\hline$<30$ and $<60$ & $4(20)$ & $1(5)$ & $0.043^{*}$ \\
\hline$>60$ and $<90$ & $13(65)$ & $11(55)$ & \\
\hline$>90$ and $<120$ & $1(5)$ & $7(35)$ & \\
\hline$>120$ and $<150$ & $2(10)$ & $1(5)$ & \\
\hline
\end{tabular}

Table 2: Comparison of the duration of post-operative swelling.

\begin{tabular}{|l|l|l|l|}
\hline $\begin{array}{l}\text { Presence of } \\
\text { post-operative } \\
\text { swelling }\end{array}$ & $\begin{array}{l}\text { Group A } \\
(\mathbf{n = 2 0})\end{array}$ & $\begin{array}{l}\text { Group } \\
(\mathbf{n = 1 2})\end{array}$ & P value \\
\hline Till 24 h & $20(100)$ & $20(100)$ & \multirow{2}{*}{0.461} \\
\hline Till 3 days & $20(100)$ & $15(75)$ & \\
\hline Till 5 days & $13(65)$ & $14(70)$ & \\
\cline { 1 - 3 } Till 7 days & $7(35)$ & $8(40)$ & \\
\cline { 1 - 3 } Till 10 days & $5(25)$ & $6(30)$ & \\
\hline Till 15 days & $3(15)$ & $2(10)$ & \\
\hline Till 1 month & $0(0)$ & $0(0)$ & \\
\hline
\end{tabular}

\section{Discussion}

The present study was done to compare the results of lag screws and mini plates in treatment of parasymphysis fracture. In our study, the incidence of parasymphysis fracture was more in males. The present study included patients within the age group of 20-45years. The goal of each of the operative treatment of mandibular fracture is to be functionally stable osteosynthesis which permits.

- Firm binding of fracture fragments.

- Quick healing without complications.

- Acceptable function and esthetics. ${ }^{[7-11]}$

The majority of patients in Group A, the time needed to complete the procedure ranges from 60 to $90 \mathrm{~min}(65 \%)$, while for the time range from 60 to $90(55 \%)$ and 90 to 120 $\min (35 \%)$ in Group B. The difference in time required for completion of the procedures between the two groups was found to be statistically significant. In Group $A$, the duration of post-operative swelling varies as it is minimum for 5 days in 13 patients $(65 \%)$ and maximum 15 days in 3 patients (15\%). In Group B, swelling was present for minimum 5 days in 14 patients $(70 \%)$ and maximum 15 days in 2 patients (10\%).

Goyal $\mathrm{M}$ et al conducted a study to compare the efficacy and surgical outcome of treatment of anterior mandibular fracture using either $2.0 \mathrm{~mm}$ titanium miniplate or $2.4 \mathrm{~mm}$ titanium lag screw technique. Results of the study showed that the mean duration of surgery (hours) was $1.97 \pm 0.52$ for group I and $1.26 \pm 0.55$ for group II. The difference was found to be statistically significant ( $\mathrm{p}$ value 0.001 ). i.e. more time was taken in case of surgery with mini-plates when compared to the lag screw. ${ }^{[12]}$ Another study conducted by Bhatnagar A et al to compare the outcome of open treatment of mandibular fracture (symphysis or parasymphysis) using lag screw or mini plate clinically as well as radiologically in young and healthy individuals of poor socioeconomic status. Results during follow up period shows a significant improvement in bite force was present in both the groups, withmmore improvement seen in the lag screw group (p\0.01). There was a significant pain reduction present in the lag screw group (p\0.01) and also masticatory efficiency showed a steadier improvement in lag screw group. ${ }^{[13]}$

\section{Conclusion}

Although the sample size is less to reach to any conclusion, the results of our study suggest that the use of lag screws in the fixation of parasymphysis fractures can be a very demanding procedure as lag screw technique for parasymphysis fracture provide several advantages over Mini plates.

\section{References}

1. Robert Bruce, Raymond Fonseca Oral \& Maxillofacial Trauma, Volume 1 ISBN 0:7216; 2566; 5

2. Tiwana PS, Kushner GM, Alpert B. Lag screw fixation of anterior mandibular fractures: a retrospective analysis of intraoperative and postoperative complications. Journal of oral and maxillofacial surgery. 2007 Jun 1;65(6):1180-5.

3. Madsen MJ, McDaniel CA, Haug RH. A biomechanical evaluation of plating techniques used for reconstructing mandibular symphysis/parasymphysis fractures. Journal of Oral and Maxillofacial Surgery. 2008 Oct 1;66(10):2012-9.

4. Ellis E 3rd. Treatment methods for fractures of the mandibular angle. Int J Oral Maxillofac Surg 1999;28:243-52.

5. Sauerbier S, Schön R, Otten JE, Schmelzeisen R, Gutwald R. The development of plate osteosynthesis for the treatment of fractures of the mandibular body - A literature review. J Craniomaxillofac Surg 2008:36:251-9.

6. Brons R, Boering G. Fractures of the mandibular body treated by stable internal fixation: A preliminary report. J Oral Surg 1970;28:40715 .

7. Thaller SR, McDonald SW (2005) Facial trauma, 1st edn. Marceld Ekkek Inc, New York, pp 381-414

8. Leonard MS. The use of lag screws in mandibular fractures. Otolaryngologic clinics of North America. 1987 Aug;20(3):479-93.

9. Ellis III E, Muniz O, Anand K. Treatment considerations for comminuted mandibular fractures. Journal of oral and maxillofacial 
surgery. 2003 Aug 1;61(8):861-70.

10. Schaaf H, Kaubruegge S, Streckbein P, Wilbrand JF, Kerkmann H, Howaldt HP. Comparison of miniplate versus lag-screw osteosynthesis for fractures of the mandibular angle. Oral Surgery, Oral Medicine, Oral Pathology, Oral Radiology, and Endodontology. 2011 Jan 1;111(1):34-40.

11. Worthington P, Champy M. Monocortical miniplate osteosynthesis. Otolaryngologic Clinics of North America. 1987 Aug;20(3):607-20.

12. Goyal M, Jhamb A, Chawla S, Marya K, Dua JS, Yadav S. A comparative evaluation of fixation techniques in anterior mandibular fractures using $2.0 \mathrm{~mm}$ monocortical titanium miniplates versus 2.4 $\mathrm{mm}$ cortical titanium lag screws. Journal of maxillofacial and oral surgery. 2012 Dec 1;11(4):442-50.

13. Bhatnagar A, Bansal V, Kumar S, Mowar A. Comparative analysis of osteosynthesis of mandibular anterior fractures following open reduction using 'stainless steel lag screws and mini plates'. Journal of maxillofacial and oral surgery. 2013 Jun 1;12(2):133-9.

Copyright: (C) the author(s), 2019. It is an open-access article distributed under the terms of the Creative Commons Attribution License (CC BY 4.0), which permits authors to retain ownership of the copyright for their content, and allow anyone to download, reuse, reprint, modify, distribute and/or copy the content as long as the original authors and source are cited.

How to cite this article: Kumar H, Thakur MK. A Comparative Evaluation between Fixation Techniques Using Lag Screws and Mini Plates in the Treatment of Parasymphysis Fracture. Asian J. Med. Res. 2019;8(1):DE01-DE03.

DOI: dx.doi.org/10.21276/ajmr.2019.8.1.DE1 